\title{
Study on Carbon Analysis and site Selection of Logistics Center under Low-carbon Environment
}

\author{
Xiaoying Qian a, ${ }^{*}$, Jin $\mathrm{Li}$, Jinxing Ying, Peihua Fu \\ School of Management and E-Business, Contemporary Business and Trade Research Center, \\ Zhejiang Gongshang University, Hangzhou, China
}

a626881851@qq.com

Keywords: Low carbon Logistics; Carbon emission; Logistics center location.

\begin{abstract}
Analyzed and quantified the low carbon supply chain carbon emissions by using life cycle method, analysis of all aspects of the decision factors, cost and carbon emission index, considering the cost targets and carbon emissions, a multi-objective mixed integer programming model is established to solve the problem. Then from the cost, customer satisfaction and other aspects of comprehensive consideration, qualitative and quantitative analysis, the study of an optimized site selection.
\end{abstract}

\section{Introduction}

Logistics, as the source of "third profit", has gradually become the hot topic of many enterprises and scholars in recent years ${ }^{[1,2]}$. However, in recent years, the proportion of logistics costs accounted for GDP high, so many governments and large enterprises into the main emission reduction targets. The direction of supply chain optimization is transformed from a single economic cost optimization to the economic and environmental effects. Therefore, the supply chain in the pursuit of high efficiency and low cost at the same time, to explore the supply chain strategy to reduce carbon emissions, the construction of low-carbon supply chain model, to achieve the overall supply chain optimal economy and environment to the maximum extent, has important theoretical and practical significance.

"The Twelfth Five-Year Guideline" period, the carbon intensity decreased $17 \%$ of the binding targets is proposed for the first time in China, the State Council issued the "12th Five-Year work plan for controlling greenhouse gas emissions" deployment of the work achieved positive results, the carbon dioxide emissions per unit of gross domestic product (called "carbon intensity") decreased about 20\%, exceeding the plan target. In November 2016 the State Council issued the "13th Five-Year work plan for controlling greenhouse gas emissions" proposed by China "13th Five-Year" period of low carbon development core goal is to 2020 , carbon intensity decreased by $18 \%$ compared to 2015 , the total amount of carbon emissions has been effectively controlled, non-greenhouse gas carbon dioxide controlled drainage efforts to further increase, significantly enhance carbon sequestration capacity.

Yuqing Wang and Maozeng $\mathrm{Li}^{[3]}$ consider the vehicle driving distance, transportation capacity and carbon emissions, and through the establishment of TSP model based on generalized minimum carbon emissions to find the optimal distribution route of low carbon export scale, different distribution path will affect the final cost and location results ${ }^{[4]}$. On the basis of weighing the total cost of logistics and the environmental impact, Wang et al ${ }^{[5]}$ constructed a multi-objective logistics network selection and transportation optimization model. In view of the supply chain management as the starting point, weigh the efficiency of supply chain and supply chain environment influence two aspects ${ }^{[6]}$, scholars put forward a fixed cost, transportation cost and carbon emissions equivalent to the cost based on the target distribution center location model ${ }^{[7]}$. Because the logistics system includes supplier production, transportation, distribution and other activities, will produce energy consumption all these activities, so the carbon added to the concept of logistics activities, the reasonable design of logistics facilities and logistics activities, has important practical significance for the realization of low carbon economy ${ }^{[8]}$.

This project is firstly analyzed and quantified by using the method of life cycle carbon emissions of low carbon supply chain, analyzes all aspects of the decision factors and cost and carbon emission 
index, considering the cost targets and carbon emissions, a multi-objective mixed integer programming model, and then considering the cost and customer satisfaction., qualitative and quantitative analysis, through the optimization of logistics center location using gravity method and breakeven analysis method, combined with the specific distribution route of logistics, location scheme research on an optimized.

\section{Analysis and calculation of carbon emissions in Logistics Center}

In the rapid development of the rapid development of the logistics system, a variety of logistics technology, facilities, the system of scientific, economic, technical and social has become the obvious characteristics of modern logistics. These characteristics are mainly embodied in the various functions of the logistics system and logistics center.

Logistics center is the node of logistics network, which has a series of functions. To grasp the meaning, type, function and status of logistics center is the foundation of logistics operation and management based on different levels of logistics facilities. In theory, the logistics center can have the following basic functions:1) the concentration of goods; 2) the primary processing; 3) the transport package; 4) the container operations; 5)the storage of goods; 6) the delivery of goods. (As shown in Figure 1).

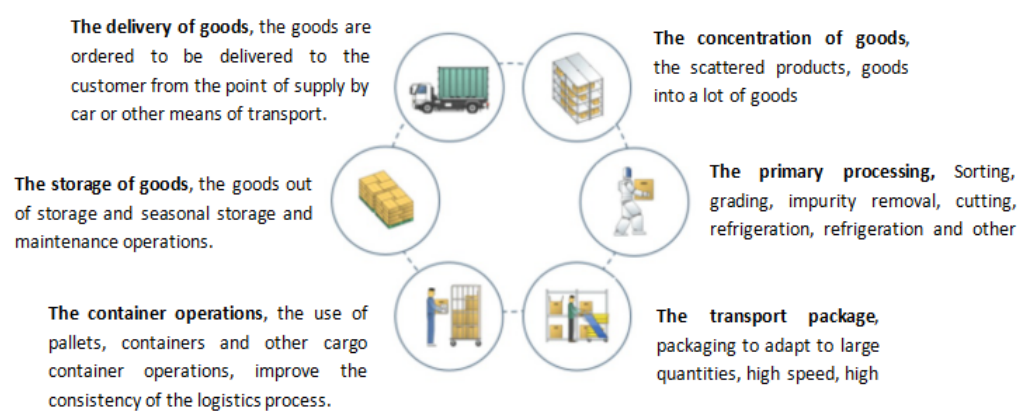

Figure 1. The basic function of logistics center

According to the basic function of the logistics center, this paper analyzes and calculates the carbon emissions of logistics storage, transportation and packaging. Through the analysis of the carbon emissions of each link, to carry out targeted "emission reduction" work, fundamentally "low carbon", in line with the requirements of society.

\section{Optimization of carbon emissions for each function of logistics center}

Based on the understanding of carbon emissions, optimize logistics carbon emissions, first need to analyze the total carbon emission in logistics, logistics and clarify the carbon emissions in all aspects, and based on reasonable assumptions and simplifications, using appropriate methods for quantitative description. Legislation and design to limit the total amount of carbon emissions, carbon trading can effectively adjust the total amount of carbon emissions, as recognized by many countries and organizations around the world ${ }^{[9]}$.

Because of the difference of packing structure of supply chain and product concentration, frequency and distance, the warehouse operation generated by the transportation there are differences, which may affect the cost of transportation fuel consumption, warehouse order strategy, average inventory and the corresponding energy consumption. Therefore, the carbon footprint of the supply chain and warehouse (order, warehouse) and transportation will be affected. In addition, due to the nature of the product and packaging differences, the demand for packaging materials are different, which may also affect the corresponding material consumption, thereby affecting the carbon emissions. In summary, carbon emission optimization according to the main logistics link, need to consider the differences in carbon emissions mainly come from the storage, transportation and packaging. For the carbon chain in the supply chain and transportation links, as shown in figure 2. 


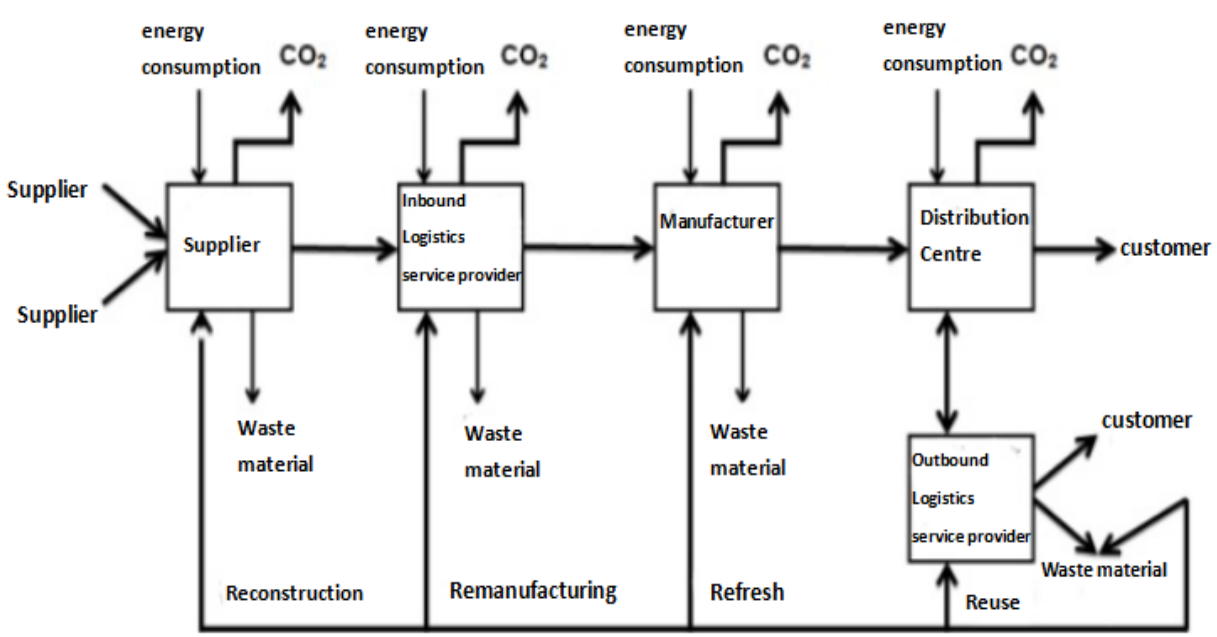

Figure 2. Schematic diagram of carbon emissions in supply chain

3.1 Storage link. For the study of carbon emissions in the process of storage, it can be considered that the main links related to carbon emissions are two aspects: order and inventory. In addition, the reduction of human resources can reduce or avoid some unnecessary carbon emissions.

3.2 Transportation link. The supply chain is about half the carbon emissions from the transport link, transport path, distance and mode of transport (including highway, railway, aviation, marine, inland etc.) will affect the carbon emissions in the process of transportation to a great extent. Based on the reasonable location of the manufacturer, the retailer and the stock center, the reasonable planning of the transportation route, the carbon emission can be greatly reduced.

3.3 Packaging link. It can be seen from the quantitative analysis of carbon emissions in the transport sector that the weight of the product will have an impact on the fuel consumption of the transportation process, and ultimately affect the carbon emissions. In addition, there are some special properties of products. In addition, the need for special goods, additional packaging, will also produce additional cartons and other packaging material needs, resulting in additional carbon emissions.

\section{Optimization of logistics center location based on carbon emission}

The location problem will involve many aspects. The main direction of our research is the selection of logistics center under low carbon logistics. Only choose a good location to meet the transportation, storage, logistics costs can be reduced. Location problem is through the establishment of a model, analyzes the cost of each link of programming to determine the optimal location of logistics center in the logistics center number to be selected, namely the location of success.

\subsection{Basic assumptions:}

1) The production volume of the logistics center to be selected is the same;

2) The fixed cost of the logistics center to be selected is known and equal;

3 ) Not allowed to appear out of stock;

4) Unit variable cost is proportional to quantity;

5) Material unit price has nothing to do with batch;

6) Instantaneous replenishment;

7) No resource constraints exist;

8) Transport vehicle models consistent.

\subsection{Constraint condition:}

1) The actual production capacity of each logistics center is less than or equal to its production capacity.

2) The demand for the product is 0 .

4.3 Model symbols and meanings:

1) $\eta_{i}$ : Carbon dioxide emissions $(\mathrm{KG})$ for each $\mathrm{i}$ item produced each time;

2) $D_{i j}$ : Indicates the number of I items to be transported in area $\mathrm{j}$; 
3) $S_{j}$ : Represents the distance from the logistics center to the area $\mathrm{j}$;

4) $K_{j i}$ : Represents the transport volume of i goods transported by logistics center to regional $\mathrm{j}$;

5) $F_{j}$ : Represents the unit transportation cost of logistics center to area j;

6) $\alpha$ : Carbon emission coefficient;

7) FC : Fixed cost; 8) TC : Total inventory cost;

\subsection{Model building:}

Transportation costs of $i$ items to $j$ consumption in the region: $\mathrm{TC}_{\text {运输i }}=\mathrm{F}_{\mathrm{j}} * K_{j i} * S_{j}$

2) The cost of carbon emissions from $i$ items: $T C_{\text {碳ij }}=\alpha * S_{\mathrm{j}} * D_{i j}$

3) Minimum total cost of objective function: $\min T C=F C+\sum_{\mathrm{i}=1, \mathrm{j}=1}^{\mathrm{n}, \mathrm{m}} T C_{\text {运输i }}+\sum_{\mathrm{i}=1, j=1}^{\mathrm{n}, m} T C_{\text {碳 } \mathrm{j}}$

4) That is: Total logistics cost $=$ fixed cost + transportation cost + carbon emission cost

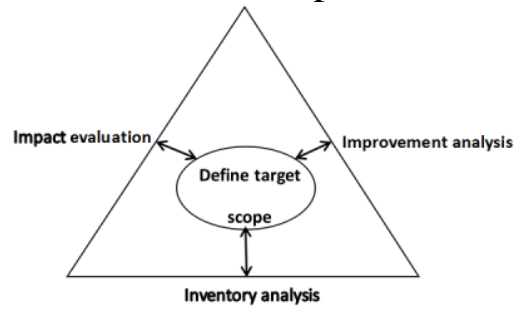

Figure 3. Life cycle assessment framework

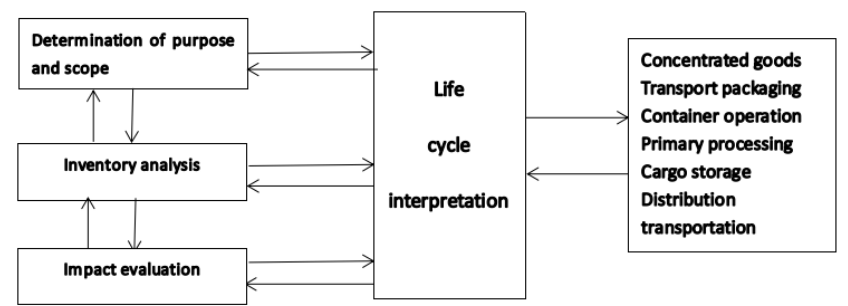

Figure 4. An important improvement of the SETAC framework for ISO

Life cycle assessment (Life-Cycle Assessment, LCA) methodology framework proposed by SETAC, The basic structure of life cycle assessment is divided into four parts: target definition and scope definition, inventory analysis, impact assessment and improvement evaluation (see Figure 3).An important improvement of the SETAC framework for ISO is to remove the improved evaluation phase.(see Figure 4).

1) Definition of objectives and scope: The main processes of the carbon emissions of the logistics center include centralized goods, transport packaging, container operations, primary processing, warehousing, distribution and transportation. The carbon emissions in logistics network can be divided into static carbon emissions and dynamic carbon emissions. Among them, the static carbon emissions mainly consider the fixed carbon emissions distribution center, dynamic carbon emission mainly consider carbon emissions supplier production, carbon emissions distribution center flow processing, carbon emissions generated during transport from the supplier to the distribution center, and from the distribution center to customers during transportation of carbon emissions.

2) Inventory analysis: According to the whole process of logistics center, the data needed for the whole life cycle assessment include the carbon emission caused by the process of each function.

3) impact assessment: Through the evaluation on each of the nodes of low carbon supply chain, clear function of each node enterprises in the supply chain, "carbon" there are many factors, including the factors of carbon emissions, carbon punishment factors, carbon trading and carbon footprint factors, factors of the carbon emission factors and carbon trading.

4) Improvement evaluation: The interpretation of the results will be summarized according to the definition of the target, the scope of the definition and the list analysis.

The comprehensive benefit analysis through the steps of the data weight and pollutant emissions, carbon emissions mainly pointed out, find out the material can save energy and reduce the waste, and 
analyzed in different solutions under the environmental and economic costs and losses, put forward a more reasonable optimization program.

\section{Example analysis}

Assumption: the logistics center only Commodity 1 and Commodity 2 and sends them to 6 different areas. The amount of carbon dioxide in the Commodity 1 and Commodity 2 of the processed products was $0.01 \mathrm{~kg}$ and $0.02 \mathrm{~kg}$, respectively. The mass of the product was $2 \mathrm{~kg}$ and $1 \mathrm{~kg}$, respectively. And the production capacity, fixed cost and unit variable cost are the same for all the logistics centers.

In this paper, according to the Australian 2012-2013 carbon tax collection standards: 23 yuan per ton of carbon emissions, equivalent to RMB 0.13326 yuan / $\mathrm{kg} /$ carbon dioxide (to 2013 exchange rate). The carbon tax rate and the national development and Reform Commission to explore the value of the carbon tax rate of 0.03 to 0.3 . According to industry standards, the size of a large vehicle has a carbon emission coefficient of $2356.3 \mathrm{~kg} \mathrm{CO} 2 / 10000 \mathrm{ton} / \mathrm{km}$. The basic conditions are shown in Table 1, Table 2, Table 3, and Table 4.

Table 1. Demand for Commodity 1 and Commodity 2 in different areas

\begin{tabular}{|c|c|c|c|c|c|c|c|}
\hline area & Northwest & Southwest & Upper Didwest & Lower Didwest & Northeast & Southeast & Aggregate demand \\
\hline Commodity 1 & 500000 & 700000 & 900000 & 800000 & 1000000 & 600000 & 4500000 \\
\hline Commodity 2 & 50000 & 90000 & 120000 & 65000 & 120000 & 70000 & 515000 \\
\hline
\end{tabular}

Table 2. Unit transportation cost of different logistics centers in different areas (USD)

\begin{tabular}{|l|c|c|c|c|c|c|}
\hline & Northwest & Southwest & Upper Didwest & Lower Didwest & Northeast & Southeast \\
\hline Logistics center 1 & 3.16 & 3.16 & 1.84 & 2.02 & 2.88 & 2.98 \\
\hline Logistics center 2 & 3.30 & 3.30 & 2.88 & 2.96 & 1.84 & 2.04 \\
\hline Logistics center 3 & 3.36 & 3.24 & 2.96 & 2.04 & 2.02 & 1.82 \\
\hline Logistics center 4 & 2.18 & 1.84 & 3.16 & 3.16 & 3.36 & 3.30 \\
\hline
\end{tabular}

Table 3. Distance of logistics center to different areas $(\mathrm{km})$

\begin{tabular}{|l|c|c|c|c|c|c|}
\hline & Northwest & Southwest & $\begin{array}{c}\text { Upper } \\
\text { Didwest }\end{array}$ & $\begin{array}{c}\text { Lower } \\
\text { Didwest }\end{array}$ & Northeast & Southeast \\
\hline Logistics center 1 & 200.00 & 150.00 & 600.00 & 400.00 & 200.00 & 300.00 \\
\hline Logistics center 2 & 300.00 & 300.00 & 500.00 & 150.00 & 400.00 & 200.00 \\
\hline Logistics center 3 & 450.00 & 200.00 & 300.00 & 350.00 & 300.00 & 250.00 \\
\hline Logistics center 4 & 300.00 & 400.00 & 200.00 & 400.00 & 100.00 & 450.00 \\
\hline
\end{tabular}

Table 4. Basic conditions of the logistics center

\begin{tabular}{|c|c|c|}
\hline Annual production capacity(unit) & 2000000 & 1000000 \\
\hline Annual fixed cost (USD) & 2200000 & 1500000 \\
\hline Variable cost (USD) & 10 & 20 \\
\hline
\end{tabular}

Through the analysis of the different conditions of linear programming, we can get the location of logistics center in the case of meeting the minimum cost $=77028989$ yuan. Location results are shown in Table 5 and Table 6:

Table 5. Commodity 1 production line

\begin{tabular}{|c|c|c|c|c|c|c|c|c|c|}
\hline & Northwest & Southwest & $\begin{array}{c}\text { Upper } \\
\text { Didwest }\end{array}$ & $\begin{array}{c}\text { Lower } \\
\text { Didwest }\end{array}$ & Northeast & Southeast & $\begin{array}{c}\text { Plants } \\
(1=\text { open })\end{array}$ & $\begin{array}{c}\text { Actual } \\
\text { production }\end{array}$ & $\begin{array}{c}\text { Maximum } \\
\text { yield }\end{array}$ \\
\hline $\begin{array}{l}\text { Logistics } \\
\text { center } 1\end{array}$ & 0.00 & 0.00 & 0.00 & 0.00 & 0.00 & 0.00 & 0 & 0 & 0 \\
\hline $\begin{array}{c}\text { Logistics } \\
\text { center } 2\end{array}$ & 0.00 & 0.00 & 900000.00 & 0.00 & 1000000.00 & 0.00 & 1 & 1900000 & 2000000 \\
\hline $\begin{array}{c}\text { Logistics } \\
\text { center } 3\end{array}$ & 0.00 & 0.00 & 0.00 & 800000.00 & 0.00 & 600000.00 & 1 & 1400000 & 2000000 \\
\hline $\begin{array}{l}\text { Logistics } \\
\text { center } 4\end{array}$ & 500000.00 & 700000.00 & 0.00 & 0.00 & 0.00 & 0.00 & 1 & 1200000 & 2000000 \\
\hline sum & 500000.00 & 700000.00 & 900000.00 & 800000.00 & 1000000.00 & 600000.00 & & 4500000 & \\
\hline $\begin{array}{l}\text { Demand } \\
\text { constraint }\end{array}$ & 0.00 & 0.00 & 0.00 & 0.00 & 0.00 & 0.00 & & & \\
\hline
\end{tabular}


Table 6. Commodity 2 production line

\begin{tabular}{|c|c|c|c|c|c|c|c|c|c|}
\hline & Northwest & Southwest & $\begin{array}{c}\text { Upper } \\
\text { Didwest }\end{array}$ & $\begin{array}{c}\text { Lower } \\
\text { Didwest }\end{array}$ & Northeast & Southeast & Plants(1=open) & $\begin{array}{c}\text { Actual } \\
\text { production }\end{array}$ & $\begin{array}{c}\text { Maximum } \\
\text { yield }\end{array}$ \\
\hline $\begin{array}{c}\text { Logistics } \\
\text { cente 1 }\end{array}$ & 0.00 & 0.00 & 0.00 & 0.00 & 0.00 & 0.00 & 0 & 0 & 0 \\
\hline $\begin{array}{c}\text { Logistics } \\
\text { cente 2 }\end{array}$ & 0.00 & 0.00 & 0.00 & 0.00 & 0.00 & 0.00 & 0 & 0 & 0 \\
\hline $\begin{array}{c}\text { Logistics } \\
\text { cente 3 }\end{array}$ & 50000.00 & 90000.00 & 120000.0065000 .00 & 120000.00 & 70000.00 & 1 & 515000 & 1000000 \\
\hline $\begin{array}{c}\text { Logistics } \\
\text { cente 4 }\end{array}$ & 0.00 & 0.00 & 0.00 & 0.00 & 0.00 & 0.00 & 0 & 0 & 0 \\
\hline sum & 50000.00 & 90000.00 & 120000.0065000 .00 & 120000.00 & 70000.00 & & 515000 & \\
\hline $\begin{array}{c}\text { Demand } \\
\text { constraint }\end{array}$ & 0.00 & 0.00 & 0.00 & 0.00 & 0.00 & 0.00 & & & \\
\hline
\end{tabular}

Among them, plants $=1$ said the establishment of the logistics center, plants $=0$ said not to establish the logistics center.

Comprehensive consideration, enterprises in considering the cost of carbon emissions, the cost is larger, but in order to be able to reduce the cost of carbon emissions, reduce carbon dioxide emissions of enterprises will gradually improve and optimize the production process route, resulting in a certain social benefits. However, most of the enterprises are unwilling to take on too much cost, so they need the support of the government and other measures to take the excess carbon emissions, which will encourage the enterprises to carry out low-carbon behavior. Therefore, considering the factors of carbon emissions in the location of logistics center, it is a mutually beneficial measure for the enterprise and the government.

\section{Conclusion}

In this paper, considering the function of link in the logistics system of carbon emissions impact on cost, combined with the "low carbon" concept, taking into account the relevant aspects of the logistics involved in carbon emissions, we optimize the location problem of logistics center, and taking into account the low carbon. And in recent years, with the increasing greenhouse effect, the world is increasingly concerned about the issue of carbon emissions. The innovation is that in China GDP high proportion of the logistics industry to reduce carbon emissions and to optimize the location, so the location of logistics center to "low carbon logistics" for the purpose of practical significance, but also provides some reference for low carbon future location.

\section{Acknowledgements}

This work is partly supported by the Zhejiang Provincial Natural Science Foundation of China (Grant No. LY17G020005, LZ14G020001), Research Project of the Collaborative Innovation Center of Modern Trade Circulation System Construction of Zhejiang Gongshang University (Grant No. 15SMGK07D).

\section{References}

[1].Elliot R, Joseph P B. Physical Distribution Service Quality in Internet Retotaling: Service Pricing, Transaction Attributes, and Firm Attributes [J]. J of Aerations Management, 2004, 21(6):651-672.

[2].Niklds A, Fredrik Se. Electronic Commerce, Marketing Channels and Logistics Platforms-A Wholesaler Perspective [J]. European J of Operation Research, 2003, 144(2): 270-279.

[3].Wang J, Xu M. Study on generalized TSP model based on minimum carbon emission [J].Journal of Mathematics in Practice and Theory.2012, 08:69-75. 
[4].Wang S, Chen L. Study on logistics center location problem in low carbon economy [J]. Logistics Engineering and Management. 2015, 37(9):4-7

[5].Wang F, Lai X, Shi N. A Multi-objective Optimization foe Green Supply China Network Design [J]. Decision Support Systems, 2011, 519(2):262-269

[6].He J. Research on model and algorithm of multi-source location routing and inventory integration in low carbon [D].2012

[7].Zhu J, Liu D. Location of logistics distribution centers considering carbon emissions [J]. Railway Purchase and Logistics | Railway Purchase Logistics, 2011, 6(4):56-57

[8].Qin X. Foreign logistics enterprises supply chain carbon footprint management innovation and inspiration [J]. Logistics Technology, 2015(2):15-18.I

[9].Li J, Zhang J. Study on the influence of carbon trading mechanism on logistics distribution path decision [J]. System Engineering Theory and Practice | System Eng. Theory Pac, 2014, 07:1779-1787. 